\section{Repercusiones en la liquidez de las microempresas ubicadas en el distrito de La Victoria, ciudad de Lima, originadas por las percepciones del Impuesto General a las Ventas en las importaciones a los repuestos vehiculares}

Repercussions on the liquidity of micro-companies located in the district of La Victoria, city of Lima, originated by perceptions of the General Sales Tax on imports to vehicle

spare parts

\begin{abstract}
RESUMEN
El presente artículo trata de ver las repercusiones en la liquidez de las microempresas ubicadas en el distrito de La Victoria, ciudad de Lima, generadas por el pago de la Percepción del Impuesto General a las Ventas que grava a las importaciones de repuestos vehiculares. El Impuesto General a las Ventas (IGV) es un tributo que grava la transferencia de bienes y servicios que se realizan en nuestro país, incluso grava los contratos de construcción, primera venta de inmuebles e importaciones. Demostrar su incidencia negativa que afecta el cumplimiento de sus compromisos de corto plazo. Todos los importadores deben adelantar el pago del Impuesto General a las Ventas en favor del fisco, para posteriormente deducirlo cuando corresponda pagar dicho impuesto, es decir cuando dichas mercancías importadas sean vendidas, o sea en otras palabras que el referido pago constituye un financiamiento que se hace en favor del estado a costa de la liquidez de los importadores. En ocasiones los empresarios recurren a préstamos bancarios para poder cumplir con esta obligación a fin de nacionalizar las mercancías importadas generándoles sobrecostos por los intereses que generan y afectando negativamente la rentabilidad de la empresa.
\end{abstract}

Palabras claves: Análisis financiero; liquidez; percepción del IGV; ratios.

\begin{abstract}
This article tries to see the repercussions on the liquidity of micro-companies located in the district of La Victoria, city of Lima, generated by the payment of the Perception of the General Sales Tax that is levied on imports of vehicle parts. The General Sales Tax (IGV) is a tax levied on the transfer of goods and services carried out in our country, including construction contracts, first sale of real estate and imports. Demonstrate its negative impact that affects the fulfillment of its short-term commitments.
\end{abstract}

Miguel Angel Chiscul

Padilla

mchisculp@unmsm.edu.pe ORCID: https://orcid.org/00000002-1463-0199

Universidad Nacional Mayor de San Marcos. Lima, Perú

(c) Los autores. Este artículo es publicado por la revista Gestión en el Tercer Milenio de la Facultad de Ciencias Administrativas Universidad Nacional Mayor de San Marcos. Este es un artículo de acceso abierto, distribuido bajo los términos de la licencia Creative Commons Atribución 4.0 Internacional (CC BY 4.0) [https://creativecommons.org/licenses/by/4.0/deed.es] que permite el uso, distribución y reproducción en cualquier medio, siempre que la obra original sea debidamente citada de su fuente original. 


\begin{abstract}
All importers must advance the payment of the General Sales Tax in favor of the Treasury, to later deduct it when it corresponds to pay said tax, that is, when said imported goods are sold, that is, in other words that the referred payment constitutes financing that is it does in favor of the state at the expense of the liquidity of the importers. Sometimes entrepreneurs resort to bank loans to be able to comply with this obligation in order to nationalize imported goods, generating cost overruns for the interest they generate and negatively affecting the profitability of the company.
\end{abstract}

Keywords: Financial analysis; liquidity; perception of the IGV; ratios.

\section{INTRODUCCIÓN}

Es una problemática que aqueja a las micro empresas importadoras de repuestos para vehículos focalizadas en el distrito de La Victoria, ciudad de Lima pues enfrentan la falta de liquidez y trayendo consigo problemas frente a las obligaciones de corto plazo que todo negocio debe afrontar como parte de sus operaciones normales, es decir el pago a sus proveedores, gastos por servicios públicos, pago de remuneraciones e impuestos laborales entre tantas obligaciones corrientes y que estas se ven seriamente afectadas por el pago de la Percepción del IGV que grava a las importaciones de las mercancías, considerando que estas empresas por el volumen de sus ventas califican como microempresas, es decir, no superan las 150 UIT (Unidades Impositivas Tributarias) calificándolas como micro negocios y que lo que más requieren estas unidades económicas es mantener un capital de trabajo que les permita operar en el día a día y que a la vez puedan alcanzar sus objetivos y metas que se establecen para poder seguir creciendo económicamente y ver capitalizar sus ganancias que redunde en un mayor capital y que a la vez le permita generar una mayor inversión y con ello lograr despegar de micro empresas a pequeñas, medianas o en una gran empresa y por ende un pago de impuesto a la renta mayor que beneficie a la recaudación fiscal y lograr mayores beneficios a todo nuestro país, pero esto de la Percepción del IGV genera obstáculos para el crecimiento de las micro empresas y trae como consecuencia que estos micro negocios no pueden salir de esa categoría por la sobre carga tributaria que representa la percepción, más aún si su devolución es un trámite que deberá de realizar siempre y cuando el contribuyente en un periodo de tres meses no tenga impuesto a pagar, es decir mayores obstáculos para poder recuperar dicho tributo y que a la postre podría terminar en una auditoria tributaria por parte de la Administración Tributaria que por experiencias vividas muchas veces la devolución puede verse mermada por las infracciones impuestas derivadas de la auditoría practicada o en el peor de los casos resulta que el contribuyente termine adeudando al estado ya que las multas impuestas resultan siendo un monto mayor al que tendría que percibir por la devolución. Esto muchas veces disuade al contribuyente a recurrir a este mecanismo por los riesgos que ello representa.

\section{OBJETIVO DEL ARTÍCULO}

A través del presente artículo anhelo que el supremo gobierno adopte medidas que puedan solucionar este problema que aqueja a las micro empresas ya sea atenuándolas es decir reduciendo de manera considerable la cuantía de las tasas existentes en la Percepción del IGV (10\%, $5 \%$ y $3.5 \%$ ), otra medida que también se puede adoptar es la suspensión de la misma es decir su inaplicabilidad de la percepción por un plazo prudente, más aún frente a la coyuntura del problema de salubridad que aqueja al mundo por la pandemia del Covid 19 de tal forma, el poder ayudar a las micro empresas que ya están afectadas económicamente por el problema de la pandemia (sobrecostos en los fletes marítimos los mismos que se han visto incrementados hasta en 7 u 8 veces su valor debido a la escasez de contenedores, reducción en la cantidad de navíos portacontenedores lo que genera que no haya espacio en los buques, aumento de precios de los commodity, pues la materia prima de los repuestos vehiculares es de cobre, zinc, estaño, aluminio entre otros así como devaluación del Yuan frente al Dólar) y en mi opinión sería la medida más acertada y adecuada la derogación 
Repercusiones en la liquidez de las microempresas ubicadas en el distrito de La Victoria, ciudad de Lima, originadas...

de la norma legal respecto a la Percepción del Igv que grava a las importaciones de las micro empresas, sería una gran ayuda a la liquidez de las empresas y lo que ello conlleva, a ya no verse obligada a buscar financiamiento que lleva un costo y que repercute en las ganancias de las empresas.

Así mismo el efecto también se vería en sus ganancias ya que tendría la liquidez que le resta dicho tributo y con ello la generación de mayores negocios que generen la rotación de inventarios y que esto permita un incremento en las ganancias de las unidades económicas que buscan crecer y por ende alcanzar bienestar a todos sus accionistas, trabajadores y estado.

\section{ARGUMENTACIÓN}

La argumentación teórica de este artículo se basa en el estudio de una microempresa abocada a las importaciones, la misma que se ubica en el distrito de La Victoria, específicamente hablamos de la empresa Corporación Woodman SAC, puesto que después de haber investigado y analizado su documentación así como sus estados financieros la sometimos al análisis financiero, a través de la aplicación de ratios financieros que analiza la liquidez entre ellos, razón corriente, prueba ácida, prueba defensiva, capital de trabajo, también se analizó el flujo de caja de la empresa, financiamiento o compromisos asumidos por la empresa, y determinamos que efectivamente la empresa afrontó problemas de liquidez en los momentos en que debía pagar las percepciones por sus importaciones realizadas, dejando una estela de compromisos impagos, el cual obligó a la empresa recurrir al financiamiento de su accionista mayoritario, dejando de lado el financiamiento externo a fin de no generar sobrecostos (intereses) considerables que a la postre incidan de manera negativa en los resultados económicos. Claro está que el accionista que financió a la empresa obtuvo más acciones debido a que dicha deuda los accionistas acordaron que se capitalice con el ánimo de darle un mayor capital de trabajo a la empresa y trayendo como consecuencia una mejor posición accionaria del referido accionista.

Para establecer los conceptos teóricos de nuestro argumento recurrimos a ciertas definiciones utilizadas y lo podemos ver plasmada respecto a la definición de índice de liquidez:
La posibilidad de hacer frente a sus pagos a corto plazo, además de confeccionar el estado de flujo de tesorería se utilizan ciertas razones. Se trata de determinar qué pasaría si la empresa le exigiera el pago inmediato de todas sus obligaciones a menos de un año. Esta prueba, aplicada a un instante de tiempo, evalúa la empresa desde un punto de vista de liquidación, en lugar de juzgarla como una empresa en marcha, caos en el cual los pasivos no se pagarían con el producto de la liquidación del activo corriente, sino con los ingresos obtenidos de las ventas. (Palomino, 2013, p. 95)

Los problemas de liquidez se genera por las percepciones del IGV que afecta a las importaciones de mercancías (repuestos para vehículos) que las microempresas realizan, esto repercute desfavorablemente en la liquidez, pues no se cuenta con los recursos necesarios para honrar sus compromisos de corto plazo, generando que la empresa caiga en incumplimiento de pagos con sus proveedores, trabajadores, servicios públicos entre otros, a raíz de esto, genere un récord crediticio adverso, a razón de ello se ven en la imperiosa necesidad de recurrir al financiamiento propio o externo, en ambos casos genera un costo (intereses) que a la postre repercutirá en el resultado económico de la empresa los mismos que se plasma en los estados financieros y por ende no se logrará alcanzar las metas y objetivos trazados o también existe la posibilidad de capitalizar dicha deuda cuando se trate de financiamiento propio es decir procedente de los socios o accionistas.

Como sabemos la entidad deberá de contar con los recursos necesarios para no caer en falta de liquidez cada vez que realiza una importación, así como plantear a los socios que de manera inmediata realicen un aporte en el capital de la empresa, cuyo fin es evitar que este problema sea permanente y una constante en la empresa.

Razón por la cual que los Estados Financieros (EE.FF.) son conceptualizados de la siguiente manera:

El producto final de la contabilidad, estados numéricos y contables, cuadros y tablas, donde se recogen en forma adecuada 
los datos dimanantes de la labor contable, que tiene como propósito general proporcionar información sobre la situación financiera, rendimiento financiero y los flujos de efectivo de una empresa, que sea útil para una amplia gama de usuarios en la toma de sus decisiones económicas (Salavarría, 2012, p. 39)

"Los estados financieros son un medio de comunicar información y no un fin, ya que no buscan convencer al lector la validez de una posición, para ello se establecen objetivos de la información financiera" (Palomino, 2013, p. 5).

Los Estados Financieros constituyen una representación estructurada de la situación financiera y del desempeño financiero de una entidad. También se pueden conceptuar los EE.FF. como cuadros que presentan en forma ordenada diversos aspectos de la situación financiera y económica de la gestión de una empresa, de acuerdo con los principios contables generalmente aceptados (PCGA). (Menis, 2012, p. 33)

Se definen a la Percepción del IGV como:

Un mecanismo de recaudación que asegura el pago del IGV, cobrándolo por adelantado, asegurando de esta manera el cumplimiento de la obligación tributaria. En ese sentido, la percepción es diseñada como un mecanismo para la formalización de la economía, en razón que opera en medios de alta evasión fiscal. (Pacherres Racuay \& Castillo Guzmán, 2016, p. 231)

El Régimen de Percepciones constituye un sistema de pago adelantado del Impuesto General a las Ventas, mediante el cual el agente de percepción (vendedor o Administración Tributaria) percibe del importe de una venta o importación, un porcentaje adicional que tendrá que ser cancelado por el cliente o importador quien no podrá oponerse a dicho cobro. (Superintendencia Nacional de Aduanas y de Administración Tributaria, s.f.)
Con respecto a la definición de análisis financiero podemos hacer referencia:

Cuando se necesita determinar el desempeño de una organización a través de las decisiones que se han tomado en el pasado, es necesario saber que se decidió en cuanto a inversión, financiamiento y operaciones del mismo, y las consecuencias de esas decisiones; esto es a lo que se llama análisis financiero. (Serna, 2009, p. 15)

Referente a la definición de ratios financiero tenemos la siguiente afirmación:

Llamados también razones financieras, son instrumentos que se emplean para analizar e interpretar los Estados Financieros de una empresa, en un periodo dado. Se calculan a partir de la combinación de los datos del Balance general y del Estado de Resultados, mediante una operación de resta - cuantas unidades excede una cantidad $\mathrm{X}$ a otra $\mathrm{Y}$ - o división -cuantas veces contiene una cantidad X a otra. (Ediciones Caballero Bustamante, 2011, p. 6)

Lo legislado en la Percepción del IGV establece que dicha carga impositiva será calculada tomando como referencia el valor de las mercancías en aduanas, a este valor se le adicionará todos los tributos propios que gravan a una importación como por ejemplo Advalorem, Impuesto Selectivo al Consumo, Impuesto General a las Ventas, Impuesto de Promoción Municipal.

Es decir, la percepción se determina de la base imponible la mismas que está compuesta por el valor de las mercancías en aduanas más los impuestos antes mencionados que se haya afectado al producto importado, representa un sobrecosto el mismo que se calcula sobre impuestos si bien es cierto que se podrá deducir del pago del IGV pero que representa un dinero inmovilizado, el mismo que no puede ser utilizado como capital de trabajo, es cierto que existe la posibilidad de solicitar su devolución pero siempre y cuando se demuestre a través de las declaraciones mensuales de impuesto que no se adeuda tributos en tres meses consecutivos, pues es evidente que está condicionada su devolución. 
La Percepción del Igv no puede compensarse con otro tributo que no sea el Impuesto General a las Ventas, generando más salida de dinero cuando se tenga que cumplir de manera mensual con los pagos a cuenta del impuesto a la renta.

Así mismo las micro empresas por su propia condición de contar con un pequeño capital en ocasiones tienen que recurrir al financiamiento, es decir, recurrir a préstamos bancarios para poder cubrir ese desface económico originando un costo debido a los intereses que se verá obligado a pagar y por ende repercutirá en las ganancias del ejercicio ya que este interés el empresario lo incorpora al costo de los productos a vender generando que se encarezca perdiendo competitividad y reflejando en los estados financieros su baja rentabilidad, así también como en el análisis de los estados financieros a través de los ratios mostraran la baja de la rentabilidad, también los días de inmovilización de existencias se incrementará y sus ratios de liquidez se verán afectados en un coeficiente menor a la unidad.

Considerando que legalmente la Percepción constituye el pago por adelantado del Igv, pues esto genera el tener que arrastrar un saldo a favor de la empresa frente a la obligación tributaria del pago del Igv, ocasionando que los recursos líquidos se encuentren inmovilizados perdiendo un costo de oportunidad frente a nuevos negocios que se podrían ejecutar, ya que su devolución legalmente es a los tres meses siempre y cuando no exista obligaciones por pagar.

\section{CONCLUSIONES}

Del presente artículo llegamos a las siguientes conclusiones:

- La Percepción del IGV que pagan las microempresas importadoras del distrito de La Victoria, ciudad de Lima, les genera pérdida de liquidez ocasionando problemas de pagos con sus obligaciones corrientes con respecto a sus proveedores, servicios públicos, remuneraciones, tributos del tesoro (pago a cuenta de renta o regularización de renta de tercera categoría o retenciones de rentas de cuarta y quinta categoría), tributos a las remuneraciones como los aportes a la seguridad social $\mathrm{y}$ aportes al sistema pensionario entre otros.

- Ciertas empresas se ven en la necesidad de recurrir a préstamos bancarios para cumplir con sus obligaciones corrientes originando sobrecostos como los intereses a los que se ve obligado a pagar y que estos son trasladados al costo de los productos perdiendo competitividad.

- Influye de manera negativa en los resultados económicos de las micro empresas ya que al perder competitividad los estados financieros mostrarán en los ratios de rentabilidad una baja considerable.

- Así mismo vemos que algunos micro empresarios se ven en la necesidad de particionar sus importaciones ya que la tasa de percepción a la primera importación es del $10 \%$, esto motiva que la primera importación sea por un monto menor y a partir de la segunda importación recién adquirirán las mercancías que necesitan ya que la tasa es del $3.5 \%$ o $5 \%$ generando sobrecostos como fletes, seguros, costos de importación referidos a la nacionalización, ya que gestiona dos importaciones perdiendo un tiempo valioso para gestionar nuevos negocios.

- Que al momento de solicitar la devolución de las percepciones muchas veces la Sunat rechaza la solicitud por que el plazo para su devolución ha prescrito, consideramos un abuso que afecta de manera perjudicial para las micro empresas.

- El tiempo para solicitar la devolución de la percepción del Igv es demasiado extenso, tres meses más el tiempo que demanda a la administración tributaria atender tu solicitud fácil sobrepasa los cien días de espera para acceder a dichos fondos inmovilizados.

- El solicitar la devolución de la Percepción del Igv en ocasiones representa un 
perjuicio económico haciendo que el empresario desista ya que la Administración tributaria tiene la facultad de practicar una auditoria y que en ocasiones la devolución se vea mermada por la imposición de multas derivadas de la auditoría por infracciones cometidas por el contribuyente y en el peor de los casos que el empresario salga debiendo al estado por las multas a pagar, es decir que la devolución solicitada no alcanza para pagar las infracciones impuestas, es decir las micro empresas salen debiendo a Sunat.

- Que si bien es cierto el establecimiento de esta normativa legal dando creación a la Percepción del Igv es para evitar la evasión tributaria pero creemos que la labor de la administración tributaria es tomar las medidas pertinentes y acciones de control para así poder luchar de manera frontal contra los evasores pero eso no tiene por qué afectar a los empresarios que de manera formal pagan sus impuesto y lo único que hace es sobre cargarlos de mayor imposición tributaria, es como reza el dicho "justos pagan por pecadores" y en mi opinión la Administración
Tributaria debe de trabajar de manera articulada y conjunta con la Fiscalía de Prevención del Delito, Policía Nacional e incluso Fuerzas Armadas para luchar contra este flagelo y derrotarlo.

\section{REFERENCIAS BIBLIOGRÁFICAS}

Ediciones Caballero Bustamante. (2011). Herramientas de Gestión Financiera. Editorial Tinco SA.

Hurtado, C. P. (2013). Análisis de los Estados Financieros. Editorial Calpa SAC.

Menis, O. C. (2012). Plan Contable Empresarial y NIIF.: Editora y Librería Jurídica Grijle EIRL.

Pacherres Racuay, A., \& Castillo Guzman, J. (2016). Manual Tributario 2016. Editorial Tinco SA.

Palomino Hurtado, C. (2013). Análisis a los Estados Financieros. Editorial Calpa SAC.

Salavarría, R. O. (2012). NIIF 2012 Y PCGE Comentarios y Aplicación Práctica. Editorial Tinco SA.

Serna, J. d. (2009). Manual de Formulas Financieras. Alfa Omega Grupo Editor SA.

Superintendencia Nacional de Aduanas y de Administración Tributaria. (s.f.). Régimen de Percepciones del IGV. Obtenido de https://orientacion.sunat.gob. pe/index.php/empresas-menu/regimen-de-percepciones-del-igv-empresas/regimen-de-percepciones-informacion-general 